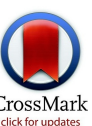

D'OR Institute for Research and Education, Rio de Janeiro, Brazil

2Department of Surgery, Johns Hopkins University School of

Medicine, Baltimore, MD, USA

${ }^{3}$ Department of Biostatistics,

Johns Hopkins Bloomberg

School of Public Health,

Baltimore, MD, USA

"Elaine and Sydney Sussman

Cardiac Catheterization

Laboratories, Cardiovascular

Division, University of Miam

Miller School of Medicine,

Miami, FL, USA

${ }^{5}$ Department of Internal

Medicine, Federal University of

Rio de Janeiro, Rio de Janeiro,

Brazil

${ }^{6}$ Department of Anesthesiology and Critical Care Medicine,

Neurology, Neurosurgery, and

Radiology, Johns Hopkins

University School of Medicine,

Baltimore, MD 21287, USA

Correspondence to:

RD Stevens rstevens@jhmi.edu

Additional material is published

online only. To view please visit

the journal online (http://dx.doi.

org/10.1136/bmj.h2538)

Cite this as: BMJ 2015;350:h2538

doi: $10.1136 /$ bmj.h2538

Accepted: 7 April 2015
OPEN ACCESS

\section{Outcome of delirium in critically ill patients: systematic review and meta-analysis}

\author{
Jorge I F Salluh, ${ }^{1}$ Han Wang, ${ }^{2}$ Eric B Schneider, ${ }^{2}$ Neeraja Nagaraja,, ${ }^{2}$ Gayane Yenokyan,, ${ }^{3}$ \\ Abdulla Damluji, ${ }^{4}$ Rodrigo B Serafim, ${ }^{1,5}$ Robert D Stevens ${ }^{6}$
}

\section{ABSTRACT}

\section{OBJECTIVES}

To determine the relation between delirium in critically ill patients and their outcomes in the short term (in the intensive care unit and in hospital) and after discharge from hospital.

\section{DESIGN}

Systematic review and meta-analysis of published studies.

\section{DATA SOURCES}

PubMed, Embase, CINAHL, Cochrane Library, and PsychINFO, with no language restrictions, up to 1 January 2015.

\section{ELIGIBILITY CRITERIA FOR SELECTION STUDIES}

Reports were eligible for inclusion if they were prospective observational cohorts or clinical trials of adults in intensive care units who were assessed with a validated delirium screening or rating system, and if the association was measured between delirium and at least one of four clinical endpoints (death during admission, length of stay, duration of mechanical ventilation, and any outcome after hospital discharge). Studies were excluded if they primarily enrolled patients with a neurological disorder or patients admitted to intensive care after cardiac surgery or organ/tissue transplantation, or centered on sedation management or alcohol or substance withdrawal. Data were extracted on characteristics of studies, populations sampled, identification of delirium, and outcomes. Random effects models and metaregression analyses were used to pool data from individual studies.

\section{RESULTS}

Delirium was identified in 5280 of 16595 (31.8\%) critically ill patients reported in 42 studies. When compared with control patients without delirium, patients with delirium had significantly higher mortality during admission (risk ratio $2.19,94 \%$ confidence interval 1.78 to $2.70 ; \mathrm{P}<0.001$ ) as well as longer durations of mechanical ventilation and lengths of stay in the intensive care unit and in hospital (standard mean differences 1.79 (95\% confidence

\section{WHAT IS ALREADY KNOWN ON THIS TOPIC}

Studies evaluating the relations between delirium in critically ill patients and mortality have yielded inconsistent results, some reporting a significant association and others not

\section{WHAT THIS STUDY ADDS}

Delirium is strongly associated with increased hospital mortality

Evidence also suggests a relation between delirium in the intensive care unit and long term cognitive impairment interval 0.31 to 3.27; $P<0.001$ ), 1.38 (0.99 to 1.77; $\mathrm{P}<0.001$ ), and 0.97 (0.61 to $1.33 ; \mathrm{P}<0.001$ ), respectively). Available studies indicated an association between delirium and cognitive impairment after discharge.

\section{CONCLUSIONS}

Nearly a third of patients admitted to an intensive care unit develop delirium, and these patients are at increased risk of dying during admission, longer stays in hospital, and cognitive impairment after discharge.

\section{Introduction}

A high proportion of adults admitted to hospital experience delirium, a pathological alteration in cognition associated with inattention, a fluctuating course, and an underlying systemic illness, metabolic imbalance, or association with a drug (or withdrawal). ${ }^{12}$ Delirium has been linked to adverse short term outcomes, including up to threefold increases hospital mortality and length of stay, ${ }^{3-5}$ which place considerable burdens on caregivers ${ }^{67}$ and healthcare services. ${ }^{89}$ Delirium can also have long term consequences, with studies indicating an association between delirium and a higher likelihood of death, ${ }^{10}$ functional disability, ${ }^{11}$ admission to residential care, cognitive impairment, ${ }^{12}$ and dementia after discharge. ${ }^{13}$ The risk of delirium is particularly high in selected subsets of hospital patients such as elderly people and those with pre-existing cognitive impairments, ${ }^{14}$ people with terminal illnesses, ${ }^{15}$ patients undergoing major surgery, ${ }^{16}$ and those who are admitted to an intensive care unit. ${ }^{17}$

The identification, prevention, and treatment of delirium are increasingly regarded as major public health priorities. ${ }^{18}$ Delirium has been described as one of the most common types of organ dysfunction encountered in intensive care, though its prevalence is variable across studies. ${ }^{319}$ Delirium can be overlooked, misdiagnosed, and its significance underestimated by healthcare providers working in intensive care. ${ }^{2021}$ Studies evaluating the relation between delirium and mortality have yielded inconsistent results, some reporting a significant association ${ }^{422-24}$ and others not. ${ }^{25-27}$

Knowledge of the true magnitude of delirium and its associated burdens in critically ill patients would allow clinicians, researchers, and policymakers to allocate much needed resources towards reducing morbidity and mortality associated with delirium. We therefore conducted a systematic review of studies evaluating delirium in intensive care. We produced quantitative estimates of the prevalence of delirium in this setting and explored the association between delirium and 
short term clinical outcomes, specifically mortality in the intensive care unit and hospital, length of stay, and duration of mechanical ventilation. We also analyzed data on long term outcomes, including cognitive impairment after admission to intensive care.

\section{Methods}

Data sources and study selection

We carried out a systematic review and meta-analysis of prospective observational studies following the recommendations of the Meta-analysis Of Observational Studies in Epidemiology (MOOSE) group. ${ }^{28}$ We searched PubMed (1966-2015), Embase (1974-2015), CINAHL (1982-2015), the Cochrane Library (2015), and PsychINFO (up to 2015). The most recent search was on 1 January 2015. We hand searched reference lists of retrieved articles, relevant review articles, and personal files. There was no language restriction. Search terms included delirium, acute confusional state, encephalopathy, organic brain syndrome, brain dysfunction, brain failure which were cross-referenced to the terms intensive care, intensive care unit, ICU, critical care, critical illness, critically ill, sepsis, acute respiratory distress, multiple organ system failure, and mechanical ventilation (see appendix 1 for details of search strategy). To be considered for inclusion, studies had to meet the following criteria:

- full length reports published in peer reviewed journals

- prospective observational cohorts or clinical trials of adult patients (aged $>16$ ) admitted to an intensive care unit

- patients were evaluated for delirium with a validated screening or diagnostic instrument: confusion

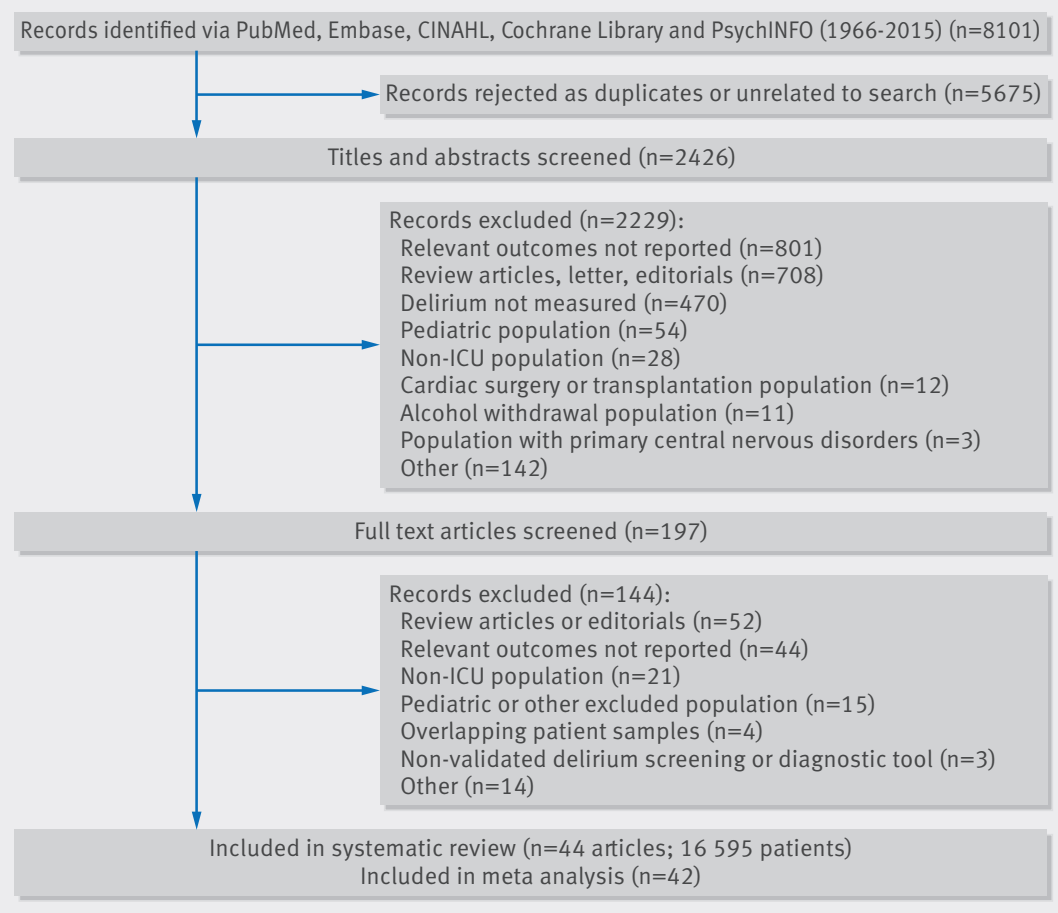

Fig 1 | Selection of studies on outcome of delirium in critically ill patients assessment method (CAM) ${ }^{29}$, confusion assessment method for the intensive care unit (CAM-ICU) ${ }^{17}$, intensive care delirium screening checklist (ICDSC) ${ }^{30}$, diagnostic and statistical manual of mental disorders 4th and 3th edition (DSM-IV and DSM-III) ${ }^{2}$, and the Neelon and Champagne (NEECHAM) confusion scale $^{31}$

- the relation between delirium and at least one of the following outcomes was reported: death in the intensive care unit or in hospital, length of stay in the intensive care unit or in hospital, duration of mechanical ventilation, or any outcome after hospital discharge.

We excluded articles if they did not have a control group of patients without delirium; if they were case studies or case series; if most enrolled patients (or the largest subgroup) had a primary central nervous system disorder (stroke, traumatic brain injury, central nervous system infections, brain tumors, recent intracranial surgery); if most enrolled patients were undergoing cardiac surgery or organ/tissue transplantation (patient subsets associated with pathophysiologically distinct forms of acute brain dysfunction); if most enrolled patients were experiencing alcohol or substance withdrawal; or if the primary study endpoint was the comparative efficacy or safety of different sedative drugs. RDS, JIFS, and AD screened citations identified by the initial search and selected potentially relevant titles for review of abstracts. From these, RDS, JIFS, and RBS then chose articles for review of full length reports. Figure 1 shows the study selection process.

\section{Data extraction and study quality assessment}

Three authors (RBS, JIFS, and AD) independently abstracted data from the selected articles. They recorded the following information (when available): study characteristics (study location, period of enrolment, type of intensive care unit, criteria for patient enrollment, number of patients enrolled, methods used to identify delirium, duration of follow-up); patients' characteristics (age, sex, premorbid cognitive and functional status, severity of illness scores, organ dysfunction scores, mechanical ventilation, renal replacement therapy); and outcomes (death in intensive care and in hospital, duration of mechanical ventilation, length of stay in intensive care, length of stay in hospital, and any reported endpoint after discharge). A fourth author (RDS) verified accuracy and reliability of the abstracted data by sampling $10 \%$ of the references selected at each stage the systematic search and evaluating extracted data against the original reference; any discrepancies were resolved by discussion among authors (RBS, JIFS, AD, RDS). If data were not reported, we planned to contact first or senior authors by email; this was not necessary as data points were readily available.

We used the Newcastle-Ottawa Scale to assess methodological quality of included studies. this scale has been validated for the assessment of observational 
studies in systematic reviews and meta-analyses. ${ }^{32} 33$ The scale evaluates three aspects of study methods: the selection of study groups (range 0-4), the comparability of groups (range 0-1), and the quality of outcome ascertainment (range 0-3). The total score ranges from 0 to 8, and an acceptable methodological design is reflected by a score of $>5$. To rate the quality of randomized controlled trials we used the validated Cochrane Risk of Bias Tool. ${ }^{34}$

\section{Patient involvement}

There was no patient involvement in the design and development of this study.

\section{Analytical approach}

We estimated patients' characteristics and outcomes (mortality (in intensive care unit and hospital), length of stay (in intensive care unit and hospital), and duration of mechanical ventilation) in those with and without delirium. The principal outcome of interest was mortality (in intensive care unit and hospital). The strength of the relation between delirium and mortality was expressed as risk ratios with 95\% confidence intervals. We selected risk ratio as a measure of effect for the binary outcome (death) as it is less prone to artificial inflation from heterogeneity than risk difference. ${ }^{35}$ Studies with zero events were entered in the analysis to include all data and reduce bias. ${ }^{36}$ To handle studies that reported zero outcomes for mortality, we performed a series of sensitivity analyses comparing Peto, Mantel-Haenszel, and inverse variance statistical methods with fixed and random effect with 0.5 continuity correction. ${ }^{37} 38$ Inverse variance and Mantel-Haenszel methods yielded identical results; we have shown the Mantel-Haenszel data in the mortality forest plot. For continuous outcomes, we calculated weighted standard mean difference based on reported means or medians. Standard deviations were imputed as summarized by Thiessen Philbrook and colleagues. ${ }^{39}$ Long term outcomes (mortality and cognitive impairment) were extracted from the selected studies; these results were summarized and crude data included in the systematic review.

We assessed heterogeneity by means of $\mathrm{I}^{2}$ statistic, which reflects the amount of heterogeneity between studies over and above the sampling variation and is robust to the number of studies and choice of effect measure. ${ }^{40}$ If the $\mathrm{I}^{2}$ statistic indicated considerable heterogeneity (Cochrane Handbook, section 9.5.2, http://handbook.cochrane.org/), we combined the summary measures across the studies using a random effects model that assumed that the included studies represent a sample from a larger population of studies. ${ }^{41}$ To explore heterogeneity between studies, we estimated the effect of study specific characteristics on outcome variables using meta-regression with the following predictors: age, proportion of women, and illness severity or organ failure score (either APACHE II or SOFA). The values of predictors were averaged across the groups with and without delirium. The outcome variable was the risk ratio of mortality, with age, sex, and severity as predictors. We assessed publication bias by inspecting funnel plots and using the modified Egger test for binary data. ${ }^{42}$ Analyses were performed with STATA version 12 and RevMan version 5.0.

\section{Results}

The literature search produced 8101 citation titles, of which we screened 2426 potentially relevant abstracts, yielding 197 articles for detailed analysis; of the latter, 44 articles (16595 patients) met our criteria and were included in the systematic review. In two instances (Ely and colleagues ${ }^{3}$ and Milbrandt and colleagues, ${ }^{8}$ and Marquis and colleagues ${ }^{43}$ and Ouimet and colleagues ${ }^{44}$ ), a single study population was reported on in two separate articles. Hence, the final systematic review included 44 reports on 42 patient samples; only those 42 samples were included in the meta-analysis.

\section{Study characteristics}

Detailed characteristics of the included studies are shown in appendix 2 . There were 40 prospective observational cohorts ${ }^{310121921-2743-67}$ and two randomized controlled trials. ${ }^{47}{ }^{68}$ Study populations ranged in size from 37 to 1824 (mean 384, median 185) patients. Twenty nine studies were conducted in mixed medical-surgical intensive care units, five studies evaluated only surgical intensive care units and two studies evaluated only medical intensive care units; seven studies evaluated only mechanically ventilated patients. Most studies (34) evaluated short term outcomes (recorded at hospital discharge or earlier). Seven studies extended follow-up to later time points, including 60 days, ${ }^{4} 180$ days, ${ }^{3} 12$ months, ${ }^{45} 465969$ and 18 months. ${ }^{48}$ Twenty five studies used multivariable approaches to adjust for the association between delirium and mortality. $34101222232543-4547495054565760616466-687071$ Details of methodological quality of included studies according to the Newcastle-Ottawa Scale are provided in appendix 3. The data originally from two randomized trials ${ }^{4768}$ were evaluated as low risk of bias on all five components of the Cochrane tool. ${ }^{34}$ The funnel plot suggested moderate publication bias in studies reporting on mortality (fig 2).

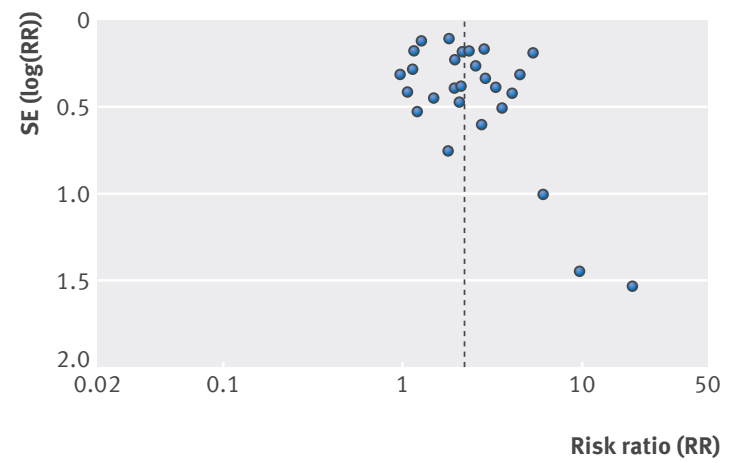

Fig 2 | Funnel plot of mortality in critically ill patients with delirium 
Delirium identification and prevalence

The table shows delirium screening and prevalence data. Delirium was identified in 5280 of 16595 patients (31.8\%). Five studies reported on cognitive or psychological function before the index admission, ${ }^{34162372}$ and three studies reported on pre-existing functional status. ${ }^{31623}$ The most common tool used for the diagnosis of delirium was the CAM-ICU, which was used in 28

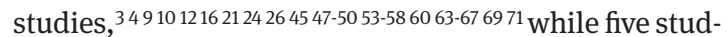
ies used the ICDSC 2527436870 . Other studies used CAM, DSM-IV, DSM-III, and the NEECHAM confusion scale.

\section{Short term outcome}

Figure 3 shows the association between delirium and mortality in the intensive care unit or in hospital. Twenty eight studies reported on mortality, and the

\begin{tabular}{|c|c|c|c|c|c|c|}
\hline \multicolumn{7}{|c|}{ Delirium screening and prevalence data from studies of critically ill patients } \\
\hline Author & $\begin{array}{l}\text { No of } \\
\text { patients } \\
\text { enrolled }\end{array}$ & $\begin{array}{l}\text { Pre-existing cognitive or } \\
\text { psychological function } \\
\text { assessed (assessment } \\
\text { method)? }\end{array}$ & $\begin{array}{l}\text { Pre-ICU functional } \\
\text { status assessed } \\
\text { (assessment method)? }\end{array}$ & $\begin{array}{l}\text { Delirium } \\
\text { assessment tool }\end{array}$ & $\begin{array}{l}\text { Physiologic } \\
\text { scoring system }\end{array}$ & $\begin{array}{l}\text { No of patients } \\
\text { with delirium (\%) }\end{array}$ \\
\hline Kishi et al, 1995 & 238 & No & No & DSM-III-R & NR & $38(15.97)$ \\
\hline Aldemir et al, 2001 & 818 & No & No & DSM-III-R & NR & $90(11.00)$ \\
\hline Dubois et al, 2001 & 198 & No & No & ICDSC & APACHE II & $38(19.19)$ \\
\hline $\begin{array}{l}\text { Ely et al, 2004; Milbrandt et al, } \\
2004\end{array}$ & 224 & Yes (mBDRS) & Yes (ADL) & CAM-ICU & APACHE II & $183(81.70)$ \\
\hline Lin et al, 2004 & 102 & No & No & CAM-ICU, DSM & APACHE III & $22(21.57)$ \\
\hline Micek et al, 2005 & 93 & No & No & CAM-ICU; & APACHE II & $44(47.31)$ \\
\hline Roberts et al, 2005 & 185 & No & No & ICDSC & APACHE II & $84(45.41)$ \\
\hline Thomason et al, 2005 & 261 & No & No & CAM-ICU & APACHE II & $125(47.89)$ \\
\hline Ranhoff et al, 2006 & 401 & Yes (MMSE) & Yes (ADL, APS) & CAM & APACHE II & $117(29.18)$ \\
\hline Balas et al, 2007 a 2008 & 114 & $\begin{array}{l}\text { Yes (IQCODE, } \\
\text { surrogate interview) }\end{array}$ & Yes (ADL, Katz) & CAM-ICU & APACHE II & $34(29.82)$ \\
\hline $\begin{array}{l}\text { Marquis et al, 2007; Ouimet et al, } \\
2007 a\end{array}$ & 537 & No & No & ICDSC & APACHE II & $189(35.20)$ \\
\hline Ouimet et al, 2007b & 764 & No & No & ICDSC & APACHE II & $243(31.81)$ \\
\hline Plaschke et al, 2008 & 37 & Yes & No & CAM-ICU & APACHE II & $17(45.95)$ \\
\hline Angles et al, 2008 & 69 & No & No & CAM-ICU & NR & $41(59.42)$ \\
\hline Lin et al, 2008 & 151 & Yes (BDRS) & No & CAM-ICU & APACHE III & $31(20.53)$ \\
\hline Van Rompaey et al, 2008 & 172 & No & No & CAM-ICU, NEECHAM & NR & $34(19.77)$ \\
\hline Lat et al, 2009 & 134 & No & No & CAM-ICU & APACHE II & $84(62.69)$ \\
\hline Page et al, 2009 & 71 & No & No & CAM-ICU & APACHE II & $22(30.99)$ \\
\hline Spronk et al, 2009 & 46 & Yes & No & CAM-ICU, & APACHE II & $23(50.00)$ \\
\hline Van Rompaey et al, 2009 & 523 & $\begin{array}{l}\text { Yes (diagnosis } \\
\text { of dementia) }\end{array}$ & No & NEECHAM & APACHE II & $155(29.64)$ \\
\hline Van den Boogaard et al, 2010 & 1740 & No & No & CAM-ICU & APACHE ॥ & $332(19.08)$ \\
\hline Tsuruta 2010 & 103 & No & No & CAM-ICU & APACHE II & $21(20.39)$ \\
\hline Shehabi 2010 & 354 & No & No & CAM-ICU & NR & $228(64.41)$ \\
\hline Salluh 2010 & 232 & No & No & CAM-ICU & SAPS III & $75(32.33)$ \\
\hline Heymann 2010 & 418 & No & No & DDS & APACHE II & $204(48.80)$ \\
\hline Girard 2010 & 77 & No & No & CAM-ICU & APACHE II & $65(84.00)$ \\
\hline Van den Boogaard et al, 2011 & 1613 & No & No & CAM-ICU & APACHE II & $411(26.00)$ \\
\hline $\begin{array}{l}\text { Van den Boogaard et al, } 2012 \\
\text { (CCM) }\end{array}$ & 915 & No & No & CAM-ICU & APACHE II & $171(18.60)$ \\
\hline Sharma et al (2012) & 140 & No & No & DSM-IV & APACHE II & $75(54.00)$ \\
\hline Tomasi et al (2011) & 162 & No & No & CAM-ICU, ICDSC & APACHE ॥ & $43(26.50)$ \\
\hline Serafim et al (2012) & 467 & No & No & CAM & APACHE II & $43(9.20)$ \\
\hline Tsuruta et al, 2014 & 180 & No & No & CAM-ICU & APACHE ॥ & $115(64.00)$ \\
\hline Almeida t al, 2014 & 170 & No & No & CAM-ICU & SAPS II, SOFA, & $161^{*}(91.00)$ \\
\hline Van den Boogaard et al, 2014 & 1824 & No & No & CAM-ICU & APACHE II & $410(22.50)$ \\
\hline Lahariya et al, 2014 & 309 & No & No & CAM-ICU, DSM-IV-TR & APACHE II, SOFA & $81(18.77)$ \\
\hline Pisani et al, 2009 & 309 & Yes & Yes & CAM-ICU & APACHE II & $\mathrm{N} / \mathrm{A}$ \\
\hline Pandharipande et al, 2013 & 821 & Yes & Yes & CAM-ICU & APACHE II, SOFA & $606(74.00)$ \\
\hline Brummel et al, 2014 & 126 & Yes & Yes & CAM-ICU & APACHE ॥ & $105(84.00)$ \\
\hline Wolters et al, 2013 & 1101 & No & No & CAM-ICU & APACHE IV, SOFA & $412(37.00)$ \\
\hline Mehta et al, 2014 & 420 & No & No & ICDSC & APACHE $\|$ & $226(53.80)$ \\
\hline Klein Klouwenberg et al, 2014 & 1112 & No & No & CAM-ICU & APACHE II & $558(50.20)$ \\
\hline Yamaguchi et al, 2014 & 126 & No & No & ICDSC & NR & $35(27.80)$ \\
\hline
\end{tabular}




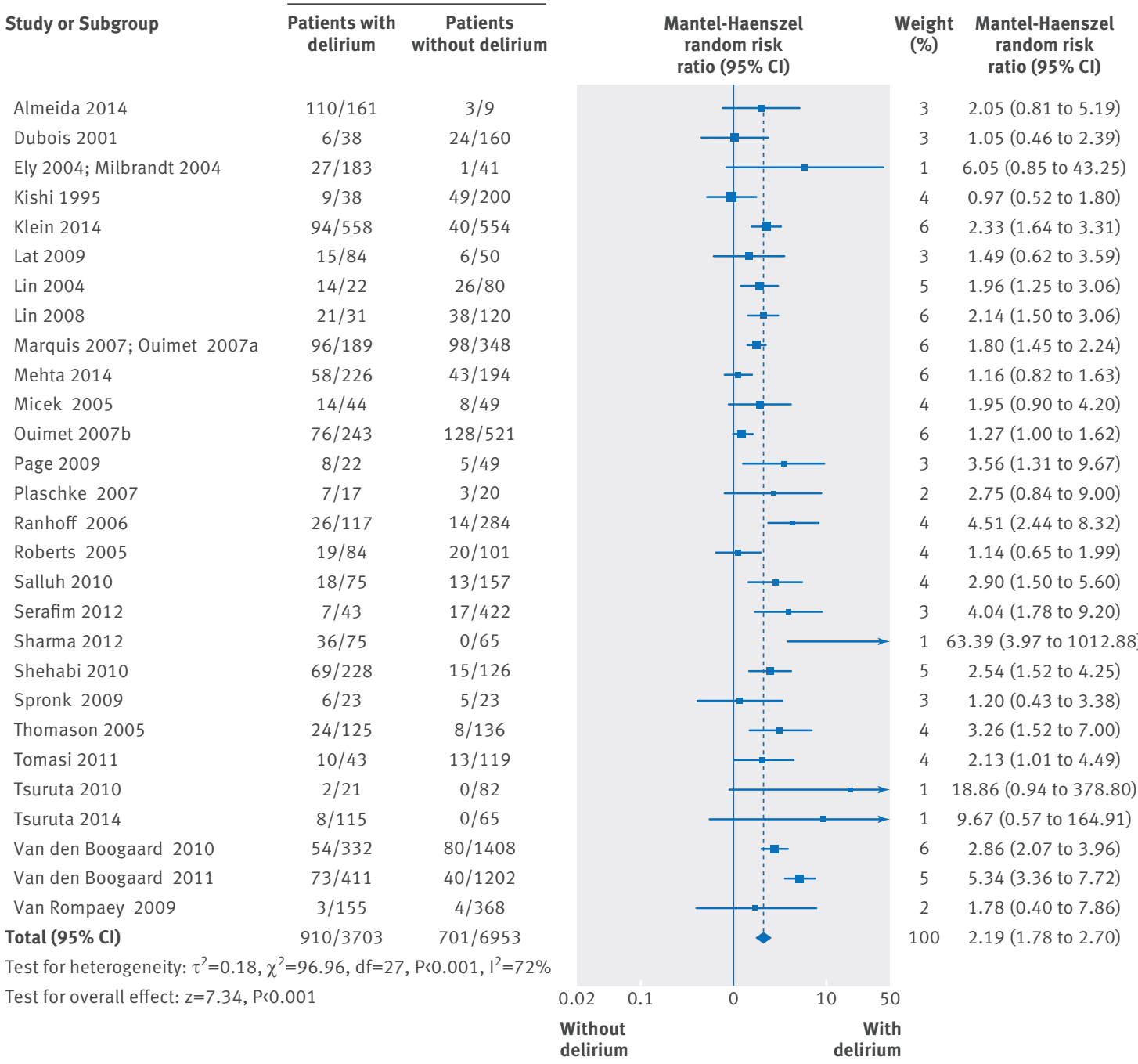

Fig 3 | Impact of delirium on hospital mortality in critically ill patients

overall risk ratio for death in patients with delirium was 2.19 (95\% confidence interval 1.78 to 2.70 ; $\mathrm{P}<0.001$ ). Severity of illness was rated with the APACHE II score in 31 studies and was higher in patients with delirium (mean 18.28 (SD 3.6) $v$ 15.72 (SD 3.7); $\mathrm{P}=0.017)$. After adjustment for age, the proportion of female patients, and APACHE scores, the adjusted risk of mortality remained higher in the delirium group (effect size 2.72, $95 \%$ confidence interval 1.75 to 3.69 ).

Twenty eight studies reported length of stay in intensive care, which was significantly longer in patients with delirium (standardized mean difference 1.38, 95\% confidence interval 0.99 to $1.77 ; \mathrm{P}<0.001)$ compared with those without delirium (fig 4). This means that patients with delirium had a mean length of stay in intensive care that was 1 day and 9 hours longer than patients without delirium. Twenty two studies reported length of stay in hospital, which was significantly longer in patients with delirium (standardized mean difference $0.97,0.61$ to 1.33 ; fig 5).

Ten studies reported duration of mechanical ventilation, with point estimates indicating a longer duration of mechanical ventilation in patients with delirium than in those without ( $1.79,0.31$ to 3.27 ; $\mathrm{P}<0.001$; fig 6)that is, the mean duration of mechanical ventilation was 1.79 days longer in patients with delirium.

\section{Outcome after discharge}

Eight studies reported follow-up after hospital discharge. 410124648496972 Two studies found increased mortality by six months in patients who had delirium when they were in intensive care $(41.2 \% v 15.4 \%$, $\mathrm{P}<0.001,{ }^{69}$ and $34 \% \vee 15 \%, \mathrm{P}=0.03^{3}$ ), and one study showed that the number of days of delirium in intensive care was significantly associated with time to death within one year after admission to intensive care unit (hazard ratio 1.10, 95\% confidence interval 1.02 to 1.18). ${ }^{10}$ In a recent prospective cohort of 1101 people who survived a critical illness, no significant association was found between delirium in intensive care and mortality or quality of life at one year, after adjustment for sex, type of admission, APACHE IV score, and the cumulative SOFA score throughout the stay in intensive care. ${ }^{49}$ 


\begin{tabular}{|c|c|c|}
\hline & & \\
\hline Study or Subgroup & $\begin{array}{l}\text { Patients with } \\
\text { delirium }\end{array}$ & $\begin{array}{c}\text { Patients } \\
\text { without delirium }\end{array}$ \\
\hline Aldemir 2001 & $10.7(13.9) / 90$ & $5(7) / 728$ \\
\hline Aldemir 2014 & $14(7) / 161$ & $13(10) / 9$ \\
\hline Angles 2008 & $7.8(1.1) / 41$ & $2.1(0.2) / 28$ \\
\hline Balas 2007 and 2008 & $8.7(11.8) / 34$ & $3(1.8) / 80$ \\
\hline Dubois 2001 & $9.3(12) / 38$ & $7(7.9) / 160$ \\
\hline Kishi 1995 & $15(21.3) / 38$ & $5(7) / 200$ \\
\hline Lat 2009 & $10(7) / 84$ & $5(3) / 50$ \\
\hline Lin 2008 & $13(7) / 31$ & $8(5) / 120$ \\
\hline Marquis 2007; Ouimet 2007a & $10.8(11.3) / 189$ & $3.9(4) / 348$ \\
\hline Mehta 2014 & $12(7) / 226$ & $8(4) / 194$ \\
\hline Micek 2005 & $9.5(5.8) / 44$ & $9.5(5) / 49$ \\
\hline Ouimet 2007b & $11.5(11.5) / 243$ & $4.4(3.9) / 521$ \\
\hline Plaschke 2007 & $6.9(6.6) / 17$ & $5(3.6) / 20$ \\
\hline Roberts 2005 & $10(7.2) / 84$ & $6.8(4.5) / 101$ \\
\hline Salluh 2010 & $22(11) / 75$ & $7(4) / 157$ \\
\hline Serafim 2012 & $6(3) / 43$ & $2(1) / 422$ \\
\hline Sharma 2012 & $7.9(4.8) / 75$ & $4.5(2.9) / 65$ \\
\hline Shehabi 2010 & $16(7) / 228$ & $4(3) / 126$ \\
\hline Spronk 2009 & $9(6) / 23$ & $5(3) / 23$ \\
\hline Thomason 2005 & $4(3) / 125$ & $3(2) / 136$ \\
\hline Tsuruta 2010 & $12(6) / 21$ & $5(3) / 82$ \\
\hline Van den Boogaard 2010 & $3(1) / 332$ & $1(1) / 1408$ \\
\hline Van den Boogaard 2011 & $6(2) / 411$ & $1(1) / 1202$ \\
\hline Van den Boogaard 2012 & $5(2) / 171$ & $1(1) / 744$ \\
\hline Van Rompaey 2008 & $17.5(14.5) / 34$ & $5(5.9) / 138$ \\
\hline Van Rompaey 2009 & $7.9(11.5) / 155$ & $1.7(2.3) / 368$ \\
\hline Wolters 2014 & $8(5) / 412$ & $3(2) / 689$ \\
\hline Yamaguchi 2014 & $7.1(6) / 35$ & $3.4(1.9) / 91$ \\
\hline Total $(95 \% \mathrm{Cl})$ & 3460 & 8259 \\
\hline Test for heterogeneity: $\tau^{2}=1.04$, & $\mathrm{c}^{2}=1636.83, \mathrm{df}=2$ & $P<0.001,\left.\right|^{2}=98 \%$ \\
\hline Test for overall effect: $z=7.02, P$ & 0.001 & \\
\hline
\end{tabular}

Fig 4 | Impact of delirium on length of stay (days) in intensive care unit in critically ill patients

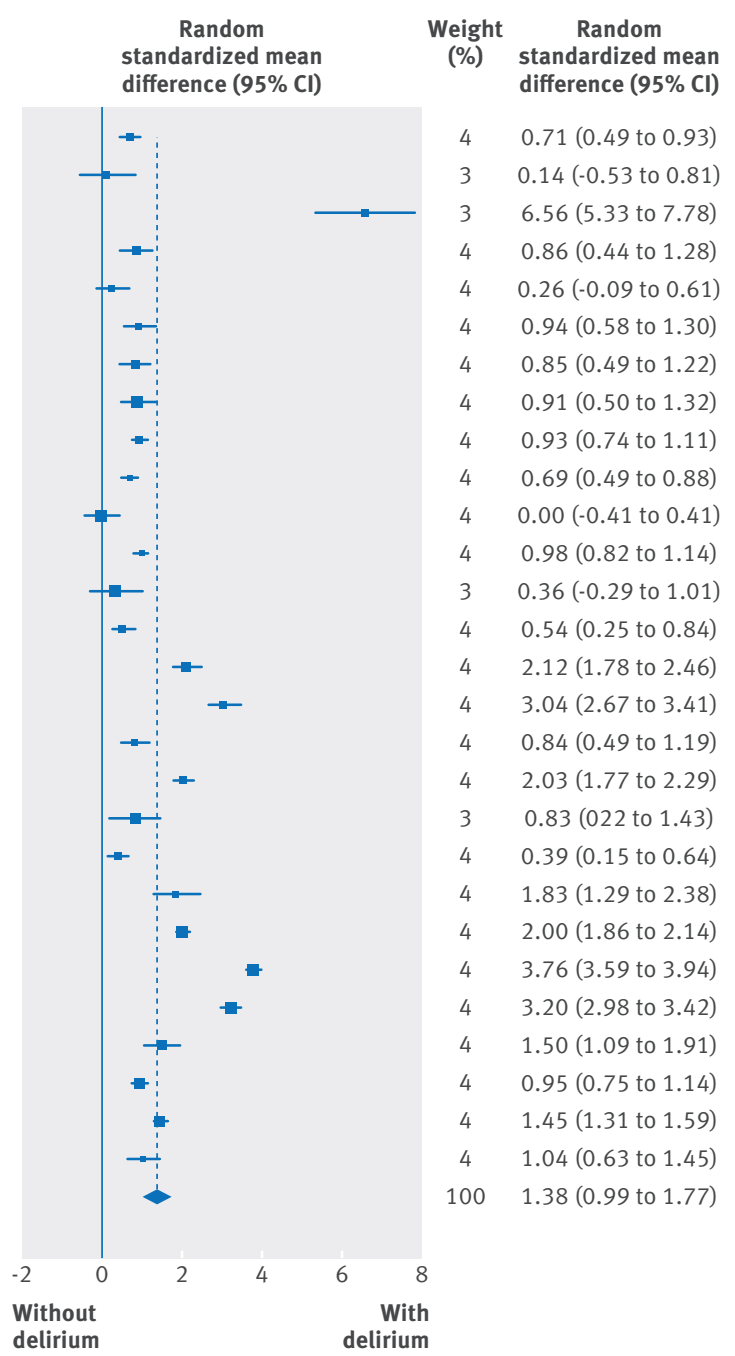

Regarding cognitive function after hospital discharge, Girard and colleagues reported that delirium was an independent predictor of worse scores on neuropsychological testing at follow-up at three months $(\mathrm{P}=0.02)$ and 12 months $(\mathrm{P}=0.03) .{ }^{46}$ Pandharipande and colleagues found that longer duration of delirium was independently associated with worse global cognition at three and 12 months $(\mathrm{P}=0.001$ and $\mathrm{P}=0.04$, respectively) and worse executive function at three and 12 months $\left(\mathrm{P}=0.004\right.$ and $\mathrm{P}=0.007$, respectively). ${ }^{12}$ Van den Boogaard and colleagues found that duration of delirium was significantly correlated to memory and naming impairments 18 months after discharge. ${ }^{48}$ Brummel and colleagues reported that in patients who survived after mechanical ventilation evaluated at 12 months, duration of delirium was associated with worse scores on activities of daily living and impaired perception of motor sensory function. ${ }^{45}$

\section{Discussion}

Principal findings

This systematic review and meta-analysis synthesized data on the prevalence of delirium in patients admitted to an intensive care unit and the association between delirium and outcomes of critically ill patients. We identified 42 studies enrolling a total of 16595 patients. Delirium was detected in nearly a third of critically ill patients and was associated with increased hospital mortality, an association that persisted after adjustment for severity of illness. Delirium was also associated with longer length of stay and longer duration of mechanical ventilation. Despite the small number of studies that evaluated outcomes at more than one time point, available data suggest an association between delirium and cognitive impairment and mortality after discharge.

\section{Strengths and limitation of study}

Our study indicates that delirium identified in the intensive care unit is strongly associated with adverse outcomes, even after adjustment for illness severity. These findings are consistent with results of a previous systematic review ${ }^{73}$ and expand them to include a much larger number of studies and patients (42 $v 14$ studies; 16595 v 5891 patients). Our data, however, still do not clarify the nature of this association, 


\begin{tabular}{|c|c|c|}
\hline \multirow[b]{2}{*}{ Study or Subgroup } & \\
\hline & $\begin{array}{l}\text { Patients with } \\
\text { delirium }\end{array}$ & $\begin{array}{c}\text { Patients } \\
\text { without delirium }\end{array}$ \\
\hline Aldemir 2001 & $15.6(16.5) / 90$ & $8.1(2.7) / 728$ \\
\hline Aldemir 2014 & $26(13) / 161$ & $36(21) / 9$ \\
\hline Angles 2008 & $15.2(1.7) / 41$ & $6.1(0.7) / 28$ \\
\hline Balas 2007 and 2008 & $17.4(12.8) / 34$ & $9.5(5.7) / 80$ \\
\hline Ely 2004; Milbrandt 2004 & $21(19) / 183$ & $11(7) / 41$ \\
\hline Lat 2009 & $17.5(13) / 84$ & $10(7) / 50$ \\
\hline $\operatorname{Lin} 2008$ & $29.5(18.5) / 31$ & $26.5(14.5) / 120$ \\
\hline Marquis 2007; Ouimet 2007a & $36.4(28.9) / 189$ & $31.6(46.5) / 348$ \\
\hline Mehta 2014 & $24(15) / 226$ & $15(8) / 194$ \\
\hline Micek 2005 & $15.5(9.5) / 44$ & $19(12.3) / 49$ \\
\hline Ouimet 2007b & $18.2(15.7) / 243$ & $13.2(19) / 521$ \\
\hline Plaschke 2007 & $22.3(16.8) / 17$ & $16.2(11.2) / 20$ \\
\hline Ranhoff 2006 & $6.7(4.3) / 117$ & $6.1(5.2) / 284$ \\
\hline Roberts 2005 & $23.3(15.6) / 84$ & $19(12.4) / 101$ \\
\hline Serafim 2012 & $26(12) / 43$ & $6(3) / 422$ \\
\hline Spronk 2009 & $29(21) / 23$ & $19(7) / 23$ \\
\hline Thomason 2005 & $5(2) / 125$ & $3(2) / 136$ \\
\hline Tomasi 2011 & $15.3(8.7) / 43$ & $10.5(7.1) / 119$ \\
\hline Van den Boogaard 2010 & $15(8) / 332$ & $8(5) / 1408$ \\
\hline Van den Boogaard 2011 & $20(10) / 411$ & $7(5) / 1202$ \\
\hline Van den Boogaard 2012 & $16(9) / 171$ & $7(5) / 744$ \\
\hline Yamaguchi 2014 & $36.3(30) / 35$ & $23(22.9) / 91$ \\
\hline Total $(95 \% \mathrm{Cl})$ & 2727 & 6718 \\
\hline
\end{tabular}

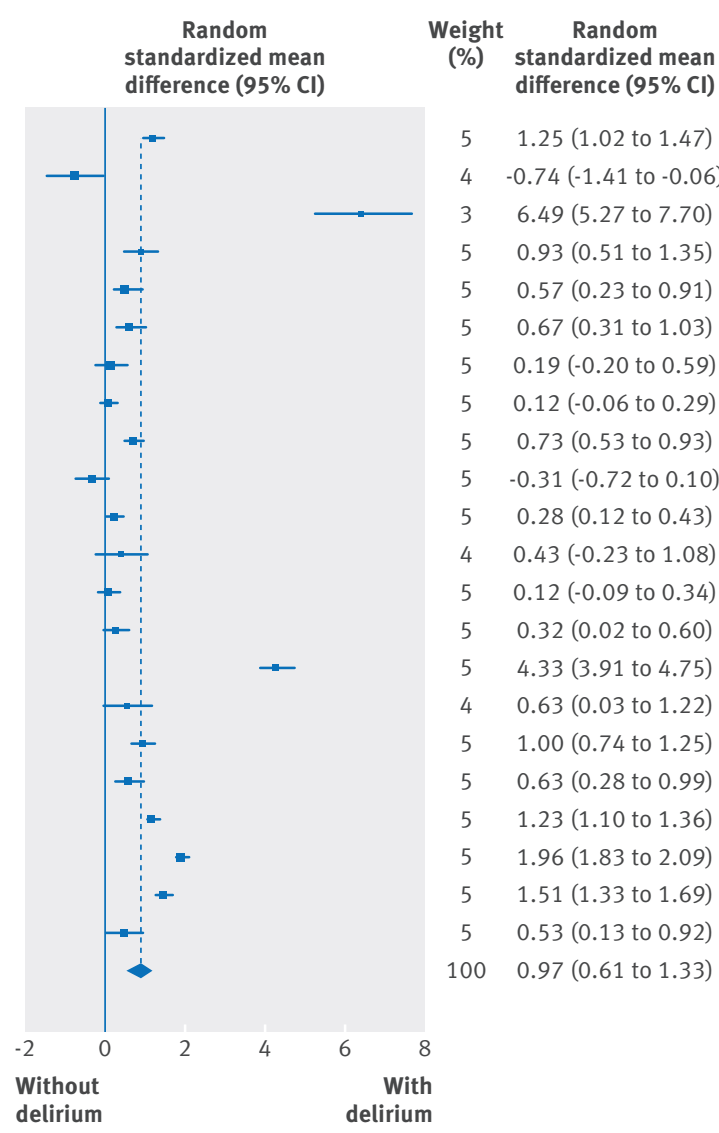

Fig 5 | Impact of delirium on length of stay (days) in hospital in critically ill patients specifically whether delirium is a condition that is causatively linked to adverse outcome or whether it is a marker of severity of disease whose link to outcome is confounded by other measured or unmeasured variables. Despite this uncertainty, the results have major practical implications and provide an evidentiary basis for the recommendations of the PAD (pain, agitation, and delirium) guidelines recently put forward by the American College of Critical Care Medicine. ${ }^{74}$ The burden of delirium could be reduced by a range of interventions such as rational titration of sedation and anesthesia, ${ }^{75}$ reduced exposure to benzodiazepines, ${ }^{76-78}$ promotion of sleep, ${ }^{72}$ early implementation of mobility and occupational therapy in

\begin{tabular}{lcc}
\cline { 2 - 3 } Study or Subgroup & $\begin{array}{c}\text { Patients with } \\
\text { delirium }\end{array}$ & $\begin{array}{c}\text { Patients } \\
\text { without delirium }\end{array}$ \\
Aldemir 2014 & $13(6.5) / 161$ & $15(5) / 9$ \\
Lat 2009 & $7.5(4) / 84$ & $3(2) / 50$ \\
Lin 2008 & $16(6) / 31$ & $6(3.5) / 120$ \\
Mehta 2014 & $13(8) / 226$ & $7(4) / 194$ \\
Micek 2005 & $6.8(4.4) / 44$ & $3.9(2.5) / 49$ \\
Shehabi 2010 & $10.7(5.8) / 228$ & $3.6(1.8) / 126$ \\
Spronk 2009 & $6(4) / 23$ & $4(1) / 23$ \\
Tsuruta 2014 & $5(3) / 115$ & $4(3) / 65$ \\
Van den Boogaard 2011 & $4.6(0.9) / 411$ & $0.3(0.2) / 1202$ \\
Van den Boogaard 2012 & $7.15(4.19) / 171$ & $3.75(1.9) / 744$ \\
Total (95\% Cl) & 1494 & 2582 \\
Test for heterogeneity: $\tau^{2}=5.62, \chi^{2}=2074.39, d f=9, P<0.001, I^{2}=100 \%$ \\
Test for overall effect: $z=2.38, P=0.02$
\end{tabular}

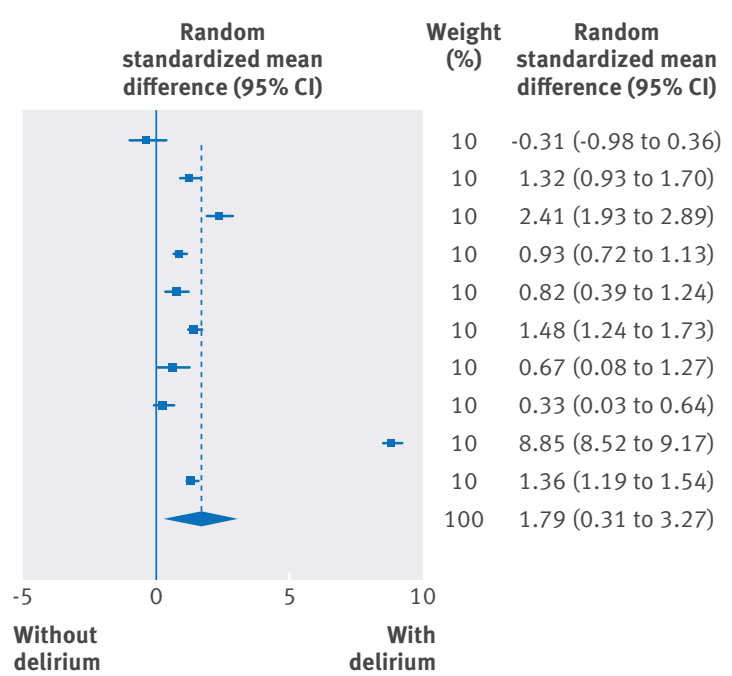

Fig 6 | Impact of delirium on duration (days) of mechanical ventilation in critically ill patients 
the intensive care unit, ${ }^{79}$ use of antipsychotic agents particularly in specific subgroups, ${ }^{80-82}$ and bundled interventions. ${ }^{83} 84$ Delirium is therefore a potentially modifiable risk factor for adverse outcomes in critically ill patients in hospital.

Given the prevalence and adverse consequences of delirium, our results underscore the need for prospective cohort studies with standardized methods to accurately and reliably detect and rate delirium and to characterize short and long term outcomes. Such studies need to be stringent in identifying all factors that could contribute to the onset, pathogenesis, and resolution of delirium associated with critical illness. Studies should be designed to allow discriminative analysis of subgroups of patients in intensive care who have different causes, severities, and durations of delirium..$^{71}$ 85-87 Specific attention should be devoted to determining endpoint measures that are relevant from a biological, clinical, and process of care standpoints. The latter might include resource utilization, long term cognitive function, psychological status, functional status, and quality of life. Additionally, large and appropriately designed clinical trials are needed to evaluate the efficacy and safety of single and bundled interventions in reducing the incidence and burden of delirium in acutely ill populations.

The present study has some limitations. First, there was considerable heterogeneity in the meta-analysis, as reflected by the $\mathrm{I}^{2}$ statistic. This is not unexpected as there were major differences between studies in the patient populations, the methods used to detect and rate delirium, and the timeframes for mortality-such differences could account for substantial differences in prevalence and mortality. Second, funnel plot asymmetry suggests the possibility of moderate publication bias in studies reporting on mortality, though this was observed in a small proportion of all patients (11\%) and was not likely to have an important impact on the conclusions. Third, we did not conduct a grey literature search, which could lead to an overestimation of the effect size. Fourth, we excluded studies of patients after cardiac surgery and organ transplantation. Phenotypes of brain dysfunction or encephalopathy in these settings are each highly distinctive in terms of epidemiology, genetic and biological determinants, pathophysiology, natural history, and outcomes; we therefore decided to remove these groups and plan to report on them separately.

Another constraint in this study is that there are potentially unmeasured confounders such as differences in the timing and frequency of assessment of delirium, in the use of sedatives, and in the medical management of critically ill patients. While advances have been made in identifying delirium in such patients, it is also apparent that the construct of delirium and the currently available assessment tools for delirium do not sufficiently characterize the range of central nervous system alterations that could be encountered in the intensive care unit. ${ }^{8}$ Subtypes of delirium including hypoactive delirium or subsyndromal delirium, for example, might not be accurately or reliably detected with available delirium instruments. ${ }^{17}{ }^{21}$ Criteria used in defining and scoring delirium differ between studies and could overlap with those used to describe other syndromes of impaired cognitive function or consciousness. In particular, patients whose level of consciousness is depressed or who are comatose might be misclassified as having delirium or alternatively might be excluded altogether from neurocognitive assessment. ${ }^{79}$

Recent work has shown that the impact of delirium on mortality in intensive care is reduced after adjustment for time varying confounders, with most of the negative impact on outcomes confined to the group with persistent delirium. ${ }^{7185}$ Although this does not diminish the overall importance of the present data, it certainly points in a new direction for clinical research. Future studies should focus on patients with persistent delirium and its impact on neurocognitive outcomes and survival. Notwithstanding these limitations, the results of this meta-analysis show a robust association between the occurrence of delirium in the intensive care unit and adverse short term outcomes.

\section{Conclusion}

Delirium is common in a broad sample of critically ill patients and is strongly associated with increased hospital mortality even after adjustment for severity of disease. Evidence also suggests a relation between delirium in the intensive care unit and long term cognitive impairment. Research is needed to unravel the biological mechanisms governing these relations and to discover strategies and treatments that will reduce the burden of acute and long term brain dysfunction in critically ill populations.

Contributors: JS and RDS designed the study, analyzed and interpreted data, and wrote the manuscript. ES, NN, and GY did the statistical analysis and interpreted the data. AD collected data. RS collected, analyzed, and interpreted data, and wrote the manuscript. RDS is guarantor.

Funding: The study was performed with institutional funding.

Competing interests: All authors have completed the ICMJE uniform disclosure form at www.icmje.org/coi_disclosure.pdf and declare: no support from any organization for the submitted work; no financial relationships with any organizations that might have an interest in the submitted work in the previous three years; no other relationships or activities that could appear to have influenced the submitted work.

Ethical approval: Not required.

Transparency: The lead author (the manuscript's guarantor) affirms that the manuscript is an honest, accurate, and transparent account of the study being reported; that no important aspects of the study have been omitted; and that any discrepancies from the study as planned (and, if relevant, registered) have been explained.

Data sharing: No additional data available.

This is an Open Access article distributed in accordance with the Creative Commons Attribution Non Commercial (CC BY-NC 4.0) license, which permits others to distribute, remix, adapt, build upon this work non-commercially, and license their derivative works on different terms, provided the original work is properly cited and the use is non-commercial. See: http://creativecommons.org/licenses/ by-nc/4.0/.

1 Inouye SK, Viscoli CM, Horwitz RI, et al. A predictive model for delirium in hospitalized elderly medical patients based on admission characteristics. Ann Intern Med 1993;119:474-81. 
2 Task Force on DSM-IV. Diagnostic and statistical manual of menta disorders: DSM-IV-TR. 4th ed. American Psychiatric Association, 2000.

3 Ely EW, Shintani A, Truman B, et al. Delirium as a predictor of mortality in mechanically ventilated patients in the intensive care unit. JAMA 2004:291:1753-62.

4 Lin S, Liu C, Wang C, et al. The impact of delirium on the survival of mechanically ventilated patients. Crit Care Med 2004;32:2254-59.

5 Pompei P, Foreman M, Rudberg MA, et al. Delirium in hospitalized older persons: outcomes and predictors. I Am Geriatr Soc 1994;42:809-15.

6 Buss MK, Vanderwerker LC, Inouye SK, et al. Associations between caregiver-perceived delirium in patients with cancer and generalized anxiety in their caregivers. J Palliat Med 2007;10:1083-92.

7 Shankar KN, Hirschman KB, Hanlon AL, et al. Burden in caregivers of cognitively impaired elderly adults at time of hospitalization: a cross-sectional analysis. J Am Geriatr Soc 2014:62:276-84.

8 Milbrandt EB, Deppen S, Harrison PL, et al. Costs associated with delirium in mechanically ventilated patients. Crit Care Med 2004;32:955-62.

9 Leslie DL, Marcantonio ER, Zhang Y, et al. One-year health care costs associated with delirium in the elderly population. Arch Intern Med 2008;168:27-32

10 Pisani MA, Kong SY, Kasl SV, et al. Days of delirium are associated with 1 -year mortality in an older intensive care unit population. Am J Respir Crit Care Med 2009;180:1092-7.

11 O'Keeffe S, Lavan J. The prognostic significance of delirium in older hospital patients. J Am Geriatr Soc 1997;45:174-8.

12 Pandharipande PP, Girard TD, Jackson JC, et al. Long-term cognitive impairment after critical illness. N Engl I Med 2013:369:1306-16

13 Witlox J, Eurelings LS, de Jonghe JF, et al. Delirium in elderly patients and the risk of postdischarge mortality, institutionalization, and dementia: a meta-analysis. JAMA 2010;304:443-51.

14 Levkoff SE, Evans DA, Liptzin B, et al. Delirium. The occurrence and persistence of symptoms among elderly hospitalized patients. Arch Intern Med 1992;152:334-40.

15 Lawlor PG, Gagnon B, Mancini IL, et al. Occurrence, causes, and outcome of delirium in patients with advanced cancer: a prospective study. Arch Intern Med 2000;160:786-94.

16 Balas MC, Happ MB, Yang W, et al. Outcomes associated with delirium in older patients in surgical ICUs. Chest 2009;135:18-25.

17 Ely EW, Inouye SK, Bernard GR, et al. Delirium in mechanically ventilated patients: validity and reliability of the confusion assessment method for the intensive care unit (CAM-ICU). JAMA 2001;286:2703-10.

18 Inouye SK, Westendorp RG, Saczynski JS. Delirium in elderly people. Lancet 2014:383:911-22.

19 Aldemir M, Ozen S, Kara IH, et al. Predisposing factors for delirium in the surgical intensive care unit. Crit Care 2001;5:265-70.

20 Van Eijk MM, van Marum RJ, Klijn IA, et al. Comparison of delirium assessment tools in a mixed intensive care unit. Crit Care Med 2009; 37:1881-5.

21 Spronk PE, Riekerk B, Hofhuis J, et al. Occurrence of delirium is severely underestimated in the ICU during daily care. Intensive Care Med 2009;35:1276-80.

22 Thomason JW, Shintani A, Peterson JF, et al. Intensive care unit delirium is an independent predictor of longer hospital stay: a prospective analysis of 261 non-ventilated patients. Crit Care 2005;9:R375-81.

23 Ranhoff AH, Rozzini R, Sabatini T, et al. Delirium in a sub-intensive care unit for the elderly: occurrence and risk factors. Aging Clin Exp Res 2006;18:440-5.

24 Page VJ, Navarange S, Gama S, et al. Routine delirium monitoring in a UK critical care unit. Crit Care 2009;13:R16

25 Dubois MJ, Bergeron N, Dumont M, et al. Delirium in an intensive care unit: a study of risk factors. Intensive Care Med 2001;27:1297-304.

26 Micek ST, Anand NJ, Laible BR, et al. Delirium as detected by the CAM-ICU predicts restraint use among mechanically ventilated medical patients. Crit Care Med 2005;33:1260-5.

27 Roberts B, Rickard CM, Rajbhandari D, et al. Multicentre study of delirium in ICU patients using a simple screening tool. Aust Crit Care 2005; 18:6-14

28 Stroup DF, Berlin JA, Morton SC, et al. Meta-analysis of observational studies in epidemiology: a proposal for reporting. Meta-analysis of observational studies in epidemiology (MOOSE) group. JAMA 2000;283:2008-12.

29 Inouye SK, van Dyck CH, Alessi CA, et al. Clarifying confusion: the confusion assessment method. A new method for detection of delirium. Ann Intern Med 1990;113:941-8

30 Bergeron N, Dubois MJ, Dumont M, et al. Intensive care delirium screening checklist: evaluation of a new screening tool. Intensive Care Med 2001;27:859-64.

31 Neelon VJ, Champagne MT, Carlson JR, et al. The NEECHAM confusion scale: construction, validation, and clinical testing. Nurs Res 1996:45:324-30.
32 Wells GA SB, O'Connell D, Peterson J, Welch V, Tugwell P. The Newcastle-Ottawa Scale (NOS) for assessing the quality of nonrandomised studies in meta-analyses. Ottawa Hospital Research Institute, 2000. www.ohrica/programs/clinical_epidemiology/ oxfordhtm.

33 Stevens RD, Dowdy DW, Michaels RK, et al. Neuromuscular dysfunction acquired in critical illness: a systematic review. Intensive Care Med 2007;33:1876-91

34 Higgins JP, Altman DG, Gotzsche PC, et al. The Cochrane Collaboration's tool for assessing risk of bias in randomised trials. $B M J$ 2011;343:d5928.

35 Fleiss JL. The statistical basis of meta-analysis. Stat Methods Med Res 1993;2:121-45.

36 Friedrich JO, Adhikari NK, Beyene J. Inclusion of zero total event trials in meta-analyses maintains analytic consistency and incorporates all available data. BMC Med Res Methodol 2007;7:5

37 Sweeting MJ, Sutton AJ, Lambert PC. What to add to nothing? Use and avoidance of continuity corrections in meta-analysis of sparse data. Stat Med 2004:23:1351-75.

38 Sankey SS, Weissfeld LA, Fine MJ, et al. An assessment of the use of the continuity correction for sparse data in meta-analysis. Commun Stat Simul Comput 1996;25:1031-56

39 Thiessen Philbrook H, Barrowman N, Garg AX. Imputing variance estimates do not alter the conclusions of a meta-analysis with continuous outcomes: a case study of changes in renal function after living kidney donation. J Clin Epidemiol 2007;60:228-40.

40 Higgins JP, Thompson SG, Deeks IJ, et al. Measuring inconsistency in meta-analyses. BMJ 2003;327:557-60.

41 DerSimonian R, Laird N. Meta-analysis in clinical trials. Control Clin Trials 1986;7:177-88.

42 Harbord RM, Egger M, Sterne JA. A modified test for small-study effects in meta-analyses of controlled trials with binary endpoints. Stat Med 2006;25:3443-57.

43 Marquis F, Ouimet S, Riker R, et al. Individual delirium symptoms: do they matter? Crit Care Med 2007;35:2533-7.

44 Ouimet S, Kavanagh BP, Gottfried SB, et al. Incidence, risk factors and consequences of ICU delirium. Intensive Care Med 2007;33: 66-73.

45 Brummel NE, Jackson JC, Pandharipande PP, et al. Delirium in the ICU and subsequent long-term disability among survivors of mechanical ventilation. Crit Care Med 2014:42:369-77.

46 Girard TD, Jackson JC, Pandharipande PP, et al. Delirium as a predicto of long-term cognitive impairment in survivors of critical illness. Crit Care Med 2010;87:1513-20.

47 Shehabi Y, Riker RR, Bokesch PM, et al. Delirium duration and mortality in lightly sedated, mechanically ventilated intensive care patients. Crit Care Med 2010;38:2311-8.

48 Van den Boogaard M, Schoonhoven L, Evers AW, et al. Delirium in critically ill patients: impact on long-term health-related quality of life and cognitive functioning. Crit Care Med 2012;40:112-8.

49 Wolters AE, van Dijk D, Pasma W, et al. Long-term outcome of delirium during intensive care unit stay in survivors of critical illness: a prospective cohort study. Crit Care 2014;18:R125.

50 Angles EM, Robinson TN, Biffl WL, et al. Risk factors for delirium after major trauma. Am / Surg 2008;196:864-70.

51 Heymann A, Radtke F, Schiemann A, et al. Delayed treatment of delirium increases mortality rate in intensive care unit patients. J Int Med Res 2010:38:1584-95.

52 Kishi Y, Iwasaki Y, Takezawa K, et al. Delirium in critical care unit patients admitted through an emergency room. Gen Hosp Psychiatry 1995;17:371-9.

53 Lat I, McMillian W, Taylor S, et al. The impact of delirium on clinical outcomes in mechanically ventilated surgical and trauma patients. Crit Care Med 2009;37:1898-905.

54 Lin SM, Huang CD, Liu CY, et al. Risk factors for the development of early-onset delirium and the subsequent clinical outcome in mechanically ventilated patients. J Crit Care 2008;23:372-9.

55 Plaschke K, von Haken R, Scholz M, et al. Comparison of the confusion assessment method for the intensive care unit (CAM-ICU) with the Intensive Care Delirium Screening Checklist (ICDSC) for delirium in critical care patients gives high agreement rate(s). Intensive Care Med 2008;34:431-6.

56 Salluh JI, Soares M, Teles JM, et al. Delirium epidemiology in critical care (DECCA): an international study. Crit Care 2010;14:R210.

57 Tsuruta R, Nakahara T, Miyauchi T, et al. Prevalence and associated factors for delirium in critically ill patients at a Japanese intensive care unit. Gen Hosp Psychiatry 2010;32:607-11.

58 Van den Boogaard M, Peters SA, van der Hoeven JG, et al. The impact of delirium on the prediction of in-hospital mortality in intensive care patients. Crit Care 2010;14:R146.

59 Van Rompaey B, Schuurmans MJ, Shortridge-Baggett LM, et al. Long term outcome after delirium in the intensive care unit. J Clin Nurs 2009;18:3349-57.

60 Almeida IC, Soares M, Bozza FA, et al. The impact of acute brain dysfunction in the outcomes of mechanically ventilated cance patients. PloS One 2014;9:e85332. 
61 Serafim RB, Dutra MF, Saddy F, et al. Delirium in postoperative nonventilated intensive care patients: risk factors and outcomes. Ann Intensive Care 2012:2:51.

62 Sharma A, Malhotra S, Grover S, et al. Incidence, prevalence, risk factor and outcome of delirium in intensive care unit: a study from India. Gen Hosp Psychiatry 2012;34:639-46.

63 Tomasi CD, Grandi C, Salluh J, et al. Comparison of CAM-ICU and ICDSC for the detection of delirium in critically ill patients focusing on relevant clinical outcomes. / Crit Care 2012;27:212-7.

64 Tsuruta R, Oda Y, Shintani A, et al. Delirium and coma evaluated in mechanically ventilated patients in the intensive care unit in Japan: a multi-institutional prospective observational study. J Crit Care 2014;29:472.e1-5.

65 Van den Boogaard M, Kox M, Quinn KL, et al. Biomarkers associated with delirium in critically ill patients and their relation with long-term subjective cognitive dysfunction; indications for different pathways governing delirium in inflamed and noninflamed patients. Crit Care 2011;15:R297.

66 Van den Boogaard M, Schoonhoven L, Maseda E, et al. Recalibration of the delirium prediction model for ICU patients (PRE-DELIRIC): a multinational observational study. Intensive Care Med 2014;40: 361-9.

67 Lahariya S, Grover S, Bagga S, et al. Delirium in patients admitted to cardiac intensive care unit with cardiac emergencies in a developing country: incidence, prevalence, risk factor and outcome. Gen Hosp Psychiatry 2014;36:156-64

68 Mehta S, Cook D, Devlin JW, et al. Prevalence, risk factors, and outcomes of delirium in mechanically ventilated adults. Crit Care Med 2015; 43:557-66.

69 Van Rompaey B, Schuurmans MJ, Shortridge-Baggett LM, et al. A comparison of the CAM-ICU and the NEECHAM Confusion Scale in intensive care delirium assessment: an observational study in non-intubated patients. Crit Care 2008;12:R16.

70 Yamaguchi T, Tsukioka E, Kishi Y. Outcomes after delirium in a Japanese intensive care unit. Gen Hosp Psychiatry 2014;36:634-6.

71 Klein Klouwenberg PM, Zaal IJ, Spitoni C, et al. The attributable mortality of delirium in critically ill patients: prospective cohort study. BM/ 2014:349:g6652

72 Kamdar BB, King LM, Collop NA, et al. The effect of a quality improvement intervention on perceived sleep quality and cognition in a medical ICU Crit Care Med 2013:41:800-9.

73 Zhang Z, Pan L, Ni H. Impact of delirium on clinical outcome in critically ill patients: a meta-analysis. Gen Hosp Psychiatry 2013;35:105-11.

74 Barr J, Fraser GL, Puntillo K, et al. Clinical practice guidelines for the management of pain, agitation, and delirium in adult patients in the intensive care unit. Crit Care Med 2013;41:263-306.

75 Sieber FE, Zakriya KJ, Gottschalk A, et al. Sedation depth during spinal anesthesia and the development of postoperative delirium in elderly patients undergoing hip fracture repair. Mayo Clin Proc 2010;85:18-26
76 Riker RR, Shehabi Y, Bokesch PM, et al. Dexmedetomidine vs midazolam for sedation of critically ill patients: a randomized trial. IAMA 2009;301:489-99.

77 Pandharipande PP, Pun BT, Herr DL, et al. Effect of sedation with dexmedetomidine vs lorazepam on acute brain dysfunction in mechanically ventilated patients: the MENDS randomized controlled trial. JAMA 2007;298:2644-53.

78 Fraser GL, Devlin JW, Worby CP, et al. Benzodiazepine versus nonbenzodiazepine-based sedation for mechanically ventilated, critically ill adults: a systematic review and meta-analysis of randomized trials. Crit Care Med 2013;41(suppl 1):S30-8.

79 Schweickert WD, Pohlman MC, Pohlman AS, et al. Early physical and occupational therapy in mechanically ventilated, critically ill patients: a randomised controlled trial. Lancet 2009;373:1874-82.

80 Wang W, Li HL, Wang DX, et al. Haloperidol prophylaxis decreases delirium incidence in elderly patients after noncardiac surgery: a randomized controlled trial*. Crit Care Med 2012;40:731-9.

81 Devlin JW, Roberts RJ, Fong JJ, et al. Efficacy and safety of quetiapine in critically ill patients with delirium: a prospective, multicenter, randomized, double-blind, placebo-controlled pilot study. Crit Care Med 2010;38:419-27.

82 Kalisvaart KJ, de Jonghe JF, Bogaards MJ, et al. Haloperidol prophylaxis for elderly hip-surgery patients at risk for delirium: a randomized placebo-controlled study. J Am Geriatr Soc 2005;53:1658-66.

83 Inouye SK, Bogardus ST Jr, Charpentier PA, et al. A multicomponent intervention to prevent delirium in hospitalized older patients. N Engl J Med 1999;340:669-76.

84 Reston JT, Schoelles KM. In-facility delirium prevention programs as a patient safety strategy: a systematic review. Ann Intern Med 2013;158:375-80.

85 Patel SB, Poston JT, Pohlman A, et al. Rapidly reversible, sedationrelated delirium versus persistent delirium in the intensive care unit. Am J Respir Crit Care Med 2014;189:658-65.

86 Widmann CN, Heneka MT. Long-term cerebral consequences of sepsis. Lancet Neurol 2014;13:630-6.

87 Hsieh SJ, Soto GJ, Hope AA, et al. The association between acute respiratory distress syndrome, delirium, and in-hospital mortality in intensive care unit patients. Am J Respir Crit Care Med 2015;191:71-8.

88 Stevens RD, Sharshar T, Ely EW. Brain disorders in critical illness: mechanisms, diagnosis, and treatment. Cambridge University Press, 2013.

Appendix 1: Search strategy

Appendix 2: Characteristics of included studied Appendix 3: Newcastle-Ottawa Scale ratings of included observational studies

(C) BMJ Publishing Group Ltd 2015 